\title{
Near-surface permeability in a supraglacial drainage basin on the Llewellyn Glacier, Juneau Icefield, British Columbia
}

\author{
L. Karlstrom ${ }^{1}$, A. Zok ${ }^{2}$, and M. Manga ${ }^{2}$ \\ ${ }^{1}$ Department of Geophysics, Stanford University, 397 Panama Mall, Stanford, CA 94305, USA \\ ${ }^{2}$ Department of Earth and Planetary Science, 307 McCone Hall, University of California at Berkeley, Berkeley, \\ CA 94720, USA
}

Correspondence to: L. Karlstrom (leifk1@stanford.edu)

Received: 10 October 2013 - Published in The Cryosphere Discuss.: 4 November 2013

Revised: 4 February 2014 - Accepted: 13 February 2014 - Published: 27 March 2014

\begin{abstract}
Supraglacial channel networks link time varying melt production and meltwater routing on temperate glaciers. Such channel networks often include components of both surface transport in streams and subsurface porous flow through near-surface ice, firn or snowpack. Although subsurface transport if present will likely control network transport efficacy, it is the most poorly characterized component of the system. We present measurements of supraglacial channel spacing and network properties on the Juneau Icefield, subsurface water table height, and time variation of hydraulic characteristics including diurnal variability in water temperature. We combine these data with modeling of porous flow in weathered ice to infer near-surface permeability. Estimates are based on an observed phase lag between diurnal water temperature variations and discharge, and independently on measurement of water table surface elevation away from a stream. Both methods predict ice permeability on a $1-10 \mathrm{~m}$ scale in the range of $10^{-10}-10^{-11} \mathrm{~m}^{2}$. These estimates are considerably smaller than common parameterizations of surface water flow on bare ice in the literature, as well as smaller than most estimates of snowpack permeability. For supraglacial environments in which porosity/permeability creation in the subsurface is balanced by porous flow of meltwater, our methods provide an estimate of microscale hydraulic properties from observations of supraglacial channel spacing.
\end{abstract}

\section{Introduction}

In the ablation zone of glaciers and ice sheets, surface meltwater channelizes and thermally erodes the icy substrate. This flowing meltwater localizes to form supraglacial streams if melt production exceeds the transport capacity of near-surface ice, firn or snowpack. Supraglacial melt transport links surface melt to subglacial hydrologic systems through englacial drainage (Fountain and Walder, 1998), so temporal variations in the rate and volume of supraglacial meltwater production have the potential to influence the basal environment and hence bulk ice movement (e.g., Iken, 1972; Müller and Iken, 1973). Large-amplitude englacial drainage events, (e.g., Das et al., 2008) as well as diurnal (e.g., Kamb et al., 1994) and seasonal (e.g., Iken and Truffer, 1997) variability in surface melting, all influence large-scale motion of ice masses.

A critical parameter to both developing and sustaining streams is the permeability of near-surface ice that controls transport of meltwater into channels. Over bare and impermeable ice or in channels, flow timescales are commonly parameterized according to an effective friction parameter (Manning's equation, e.g., Arnold et al., 1998). However, in some settings there is also a layer of fractured, partially melted or otherwise weathered bare ice in the near surface through which porous flow of melt may occur (Fountain and Walder, 1998). Because channelized flow moves quite rapidly (typical velocities up to $\sim 1 \mathrm{~m} \mathrm{~s}^{-1}$ ), subsurface porous flow if present will be the limiting factor for propagation of diurnal signals into the near-surface glacier hydrologic system. Permeability varies as a function of depth 
because melting attenuates with the decay of solar radiation in the subsurface and percolating meltwater can refreeze (Pfeffer et al., 1991), in addition to possible compaction effects. Permeability will also vary with altitude and season as surface snow transitions to bare ice down glacier (Braithwaite et al., 1994).

Ice permeability sets the transport efficiency of the supraglacial system, a quantity of interest in large-scale and short-time water budgets for glaciers and ice sheets (Rennermalm et al., 2013). Measurements of firn and weathered ice permeability have been conducted on $\mathcal{O}(0.1-1) \mathrm{m}$ scale samples (e.g., Fountain, 1989; Schneider, 1999; Albert et al., 2000). But because permeability is often a scale-dependent material property (e.g., Schulze-Makuch et al., 1999), measurements on larger scales should provide better characterization of hydraulic transport relevant to supraglacial channels. Such measurements may also be more relevant for relating permeability to porosity measurements taken on larger (100-1000 m) scale (e.g., Morris and Wingham, 2011; Brown et al., 2012). Intermediate (1-100 m)-scale permeability relevant for supraglacial stream channel formation and spacing (Marston, 1983) is not well constrained.

Here we develop novel methods to infer field-scale permeability in supraglacial systems, and present measurements of a supraglacial drainage basin high in the ablation zone of the Llewellyn Glacier on the Juneau Icefield, British Columbia, Canada, over four days in August 2010 aimed at characterizing both surface and subsurface components of the supraglacial network. These measurements reveal how near-surface permeability is expressed in the distribution and time variation of melt transport. We measure time-varying discharge, water temperature and geometrical properties of a supraglacial drainage basin including channel aspect ratio, channel spacing and the height of the subsurface water table away from channels. We then develop two methods to infer near-surface permeability, on a length scale of $1-10 \mathrm{~m}$ that is relevant to channel development at the Llewellyn Glacier site. One method is based on modeling the elevation of the subsurface water table that extends perpendicular to channels, while the other uses a phase shift observed between stream water temperature and discharge to infer a subsurface transport lag. Both methods result in similar estimates for permeability of near-surface ice. We end by illustrating how these methods could be extended via remote sensing observations to large-scale supraglacial drainage networks such as those on the western Greenland Ice Sheet.

\section{Site summary and methods}

The Llewellyn Glacier drains the Juneau Icefield, on the eastern side of the North American Continental Divide (Fig. 1). Because of the local rain shadow and relatively high elevation $(1440 \mathrm{~m})$, the primary input to the supraglacial hydrologic network at this site is locally produced meltwater rather

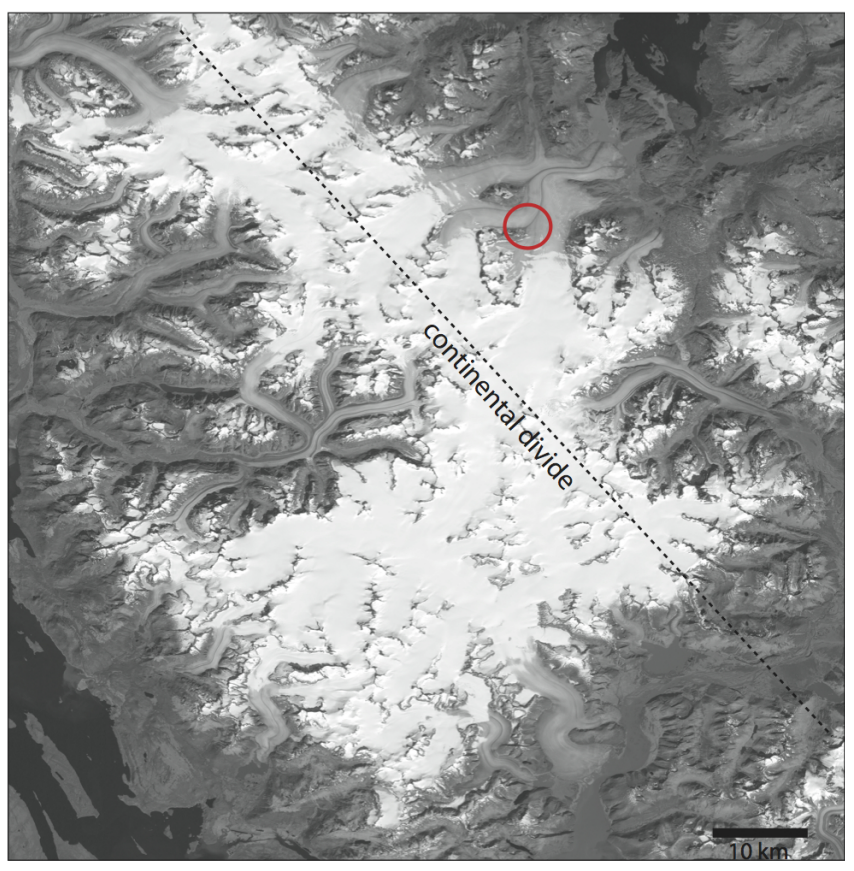

Fig. 1. Landsat 7 image (taken 15 August 2001) of the Juneau Icefield. The Llewellyn Glacier study site is located at $59^{\circ} 4^{\prime} 36.83^{\prime \prime} \mathrm{N}$, $134^{\circ} 7^{\prime} 24.54^{\prime \prime} \mathrm{W}$, indicated by the solid red circle.

than rain. Average yearly rainfall in Atlin, British Columbia, Canada $(60 \mathrm{~km}$ East and $450 \mathrm{~m}$ lower than the Llewellyn site) is $0.192 \mathrm{~m} \mathrm{yr}^{-1}$ (http://www.theweathernetwork.com). Our study site is a drainage basin several kilometers down glacier from the equilibrium line near a medial moraine (Fig. 2a), exhibiting supraglacial channels that draw water from a layer of weathered, partially melted surface ice (e.g., Müller and Keeler, 1969). In the time frame of our study (47 August 2010), we observed the transient snow line (TSL) at elevations $\sim 75-100 \mathrm{~m}$ higher than our study site, implying $\sim 3$ weeks of bare ice exposure prior to our study if TSL migration rates measured at other glaciers on the Juneau Icefield ( 4-5 $\mathrm{m} \mathrm{day}^{-1}$ in August 2010, Pelto, 2011; Pelto et al., 2013) are also assumed for our site. Fractures and crevasses in this ice-marginal area are rare, with spacing much larger than typical stream spacing.

Although some inheritance of channels may occur, many supraglacial channels form anew each year when melt production exceeds subsurface transport capacity and ensuing surface flow locally enhances thermal erosion (Fig. 2b). Because of rapid glacier surface melting (several $\mathrm{cm} \mathrm{day}^{-1}$ our study period coincided with higher than average temperatures as recorded in Atlin), we observed that channels in this environment form and become abandoned on day- to severalday timescales (Fig. 2c), creating a hummocky glacier surface topography in the upper parts of the drainage basin. This topography reflects a competition between localized erosion by streams and large-scale surface lowering. The Llewellyn 


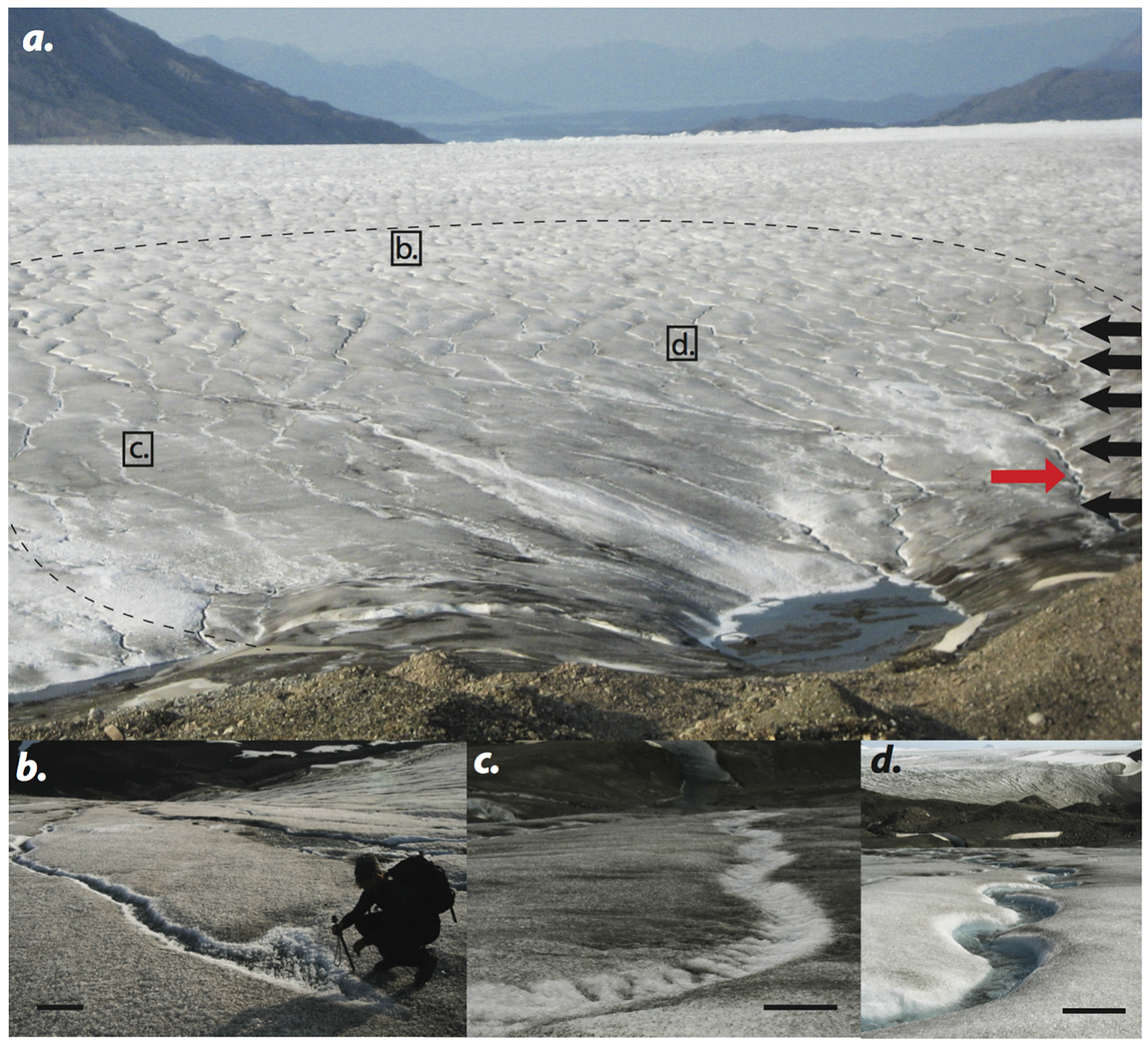

Fig. 2. (a) Marginal region of the Llewellyn Glacier that contains the study drainage basin (dashed line), photo taken from medial moraine. Black arrows indicate starting locations of survey transects, while red arrow is the stream in which the DTS temperature sensor was deployed. Boxed letters provide approximate locations of photographs in subsequent panels. (b) Inception of a supraglacial channel high in the upper study drainage basin, with porous icy substrate surrounding. (c) Recently abandoned channel, note difference in color between recently wetted channel ice and the glacier surface. (d) Example of a highly regular meandering reach. Black scale bars in panels (b-d) are approximately $50 \mathrm{~cm}$.

study site thus is well suited for a short duration and spatially focused study: supraglacial transport is widespread, the channel networks evolve rapidly, and both surface and subsurface meltwater transport are important.

We observed supraglacial streams during four consecutive days. During this time we conducted a survey of the study drainage basin (Fig. 3) by traversing the drainage basin at five elevations, recording stream channel positions, channel width/depth, and hydraulic activity. Elevations of our transects are indicated by black arrows in Fig. 2a, and we used a handheld GPS unit to ensure that a transect crossed the drainage basin at a constant altitude (relative error about $10 \mathrm{~m}$ ). We also performed point measurements of stream discharge as well as continuous (1-2 day duration) monitoring of one stream, measuring water temperature, and stream discharge. Meteorological data were gathered continuously.
Surveying of streams within the basin was accomplished with a combination of measuring tapes/sticks and a laser range finder (TruPulse 200B) with $\sim 1 \mathrm{~cm}$ accuracy. Stream long profiles were measured using a Trimble R3 geodetic GPS unit (L1 band) in kinematic survey mode. Kinematic survey positions are accurate to $1 \mathrm{~cm}$ in the horizontal and $2 \mathrm{~cm}$ vertically.

Stream discharge and depth were measured using a Sontek Flowtracker handheld acoustic Doppler velocimeter to measure mean velocity. We used the standard point velocity measurement at 0.6 the total depth to infer average stream water velocity. Error on these measurements is $\sim 0.1 \mathrm{~m} \mathrm{~s}^{-1}$, $\sim 10 \%$ of measured velocities for large streams in our study site, but similar to measured velocities high in the basin. Channel width was obtained with a measuring tape, varying less than $0.01-0.02 \mathrm{~m}$ over a similar distance up- and 
downstream of the measurement (channel widths are generally slowly varying). All streams surveyed in this study were $>0.05 \mathrm{~m}$ deep at peak discharge. Melt rate at both sites was estimated by observing bulk ice lowering around ice screws inserted perpendicular to the glacier surface, although we acknowledge that this method involves significant errors and we use these measurements only as an order of magnitude estimate for ablation.

In situ subsurface transport is difficult to monitor, and to help overcome this difficulty we employed a water temperature monitor, a distributed temperature sensor (DTS), to obtain a stream temperature time series that represents an indirect but highly accurate and noninvasive means of inferring upstream flow variation. We monitored stream water temperature continuously in one stream (indicated by the red arrow in Fig. 2a). The DTS instrument is a cable thermometer that operates by firing short laser pulses down a length of fiber optic cable with a sensor measuring and integrating the spectrum of backscattered light. Light scattered by electrons in low-energy states returns to the detector slightly redshifted (Stokes scattering), while light scattered by electrons in highenergy states returns slightly blueshifted (anti-Stokes scattering). The temperature of a particular length of cable can be inferred from the amplitude ratio of the Stokes/anti-Stokes signals (Tyler et al., 2009) integrated over a specified time period.

Attenuation mechanisms within the cable itself are generally frequency dependent, so laser pulses are sent through the cable in both directions to allow the effects of differential attenuation to be measured and corrected for. To reduce the effects of instrument drift during a long deployment, calibration was performed continuously by comparing temperature measurements of an ice-water bath (mixed by a motorized fish tank propeller) using both the DTS and a PT100 thermistor. A total of $10 \mathrm{~m}$ of cable was placed in the ice bath. We integrate DTS temperature measurements over $30 \mathrm{~min}$ time intervals to obtain a temperature resolution better than $0.05^{\circ} \mathrm{C}$ with a spatial resolution of $1 \mathrm{~m}$. We then average measurements over the length of submerged (white colored) cable to get mean stream water temperature as a function of time. We ensure that during the day the cable is submerged in several centimeters of water to control for the effect of radiative cable heating by solar radiation. At night some cable is exposed, but the effects of radiation are then at a minimum, and it is easy to distinguish sections of cable exposed to the air by their higher temperatures.

Subsurface water table measurements were also conducted through coring of near-surface ice, a direct although intrusive method for inferred subsurface permeability. Several 20-25 cm deep cores were taken in a straight line perpendicular to a stream at midday on a cloudless day, using a $\sim 5 \mathrm{~cm}$ diameter pipe with a serrated end to facilitate coring. Other point cores were taken in the surroundings to verify the general level of the water table, but we focused detailed measurements on one profile.
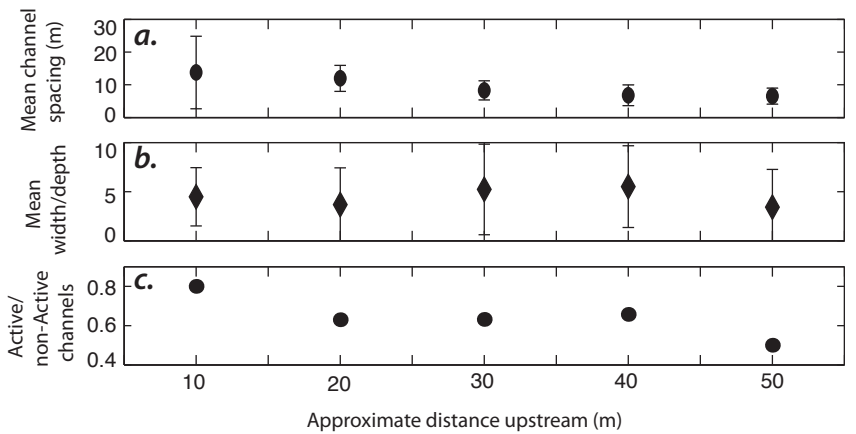

Fig. 3. Network characteristics of the Llewellyn drainage basin shown in Fig. 2b, higher numbers moving upstream. (a) Mean channel spacing (inverse of channel density) with standard deviation error bars (b). Mean width to depth of active channels, with standard deviation. (c). Ratio of active to non-active (abandoned) channels.

Finally, we installed an eKo meteorological station that measured continuous time series of wind speed and direction, net solar radiation, air temperature and relative humidity in the drainage basin. Meteorological measurements were carried out every $30 \mathrm{~s}$ for $\sim 2$ days, although instrument malfunction during the time period of DTS temperature measurements prevented complete overlap in data sets. We use daily averages of these data in what follows. For the period of our observation we take the representative temperature of $7.8^{\circ} \mathrm{C}$, relative humidity of $78 \%$, and wind speed of $6.8 \mathrm{~m} \mathrm{~s}^{-1}$.

\section{Results}

A coarse survey of the study site's supraglacial drainage basin (Fig. 2a, approximate area $0.07-0.08 \mathrm{~km}^{2}$ ) reveals ubiquitous small streams with average daytime discharge of $\sim 0.01 \mathrm{~m}^{3} \mathrm{~s}^{-1}$. A close coupling of melting to solar forcing (e.g., Marston, 1983) means that discharge at this site is strongly diurnal. Channel density decreases downstream (Fig. 3a), and streams high in the catchment exhibit close, regular spacing. Channel width to depth remains roughly constant throughout the drainage basin (Fig. 3b), consistent with the observation that the range in discharge is small. Hydraulic geometry of supraglacial streams does seem to vary as a function of discharge in general (Knighton, 1981), so it may also evolve seasonally as melt rates and the nature of the icy substrate change.

Abandoned channels are more common towards the top of the catchment compared to the bottom (Fig. 3c), indicative of active channel rearrangement. We note that the short duration of our study precludes a detailed study of the active rearrangement of streams. However, the nearness of our site to the TSL during the study period implies that supraglacial streams could not have been developing over bare ice for more than 2-3 weeks. Although they may have developed initially under snowpack, the small size of these 

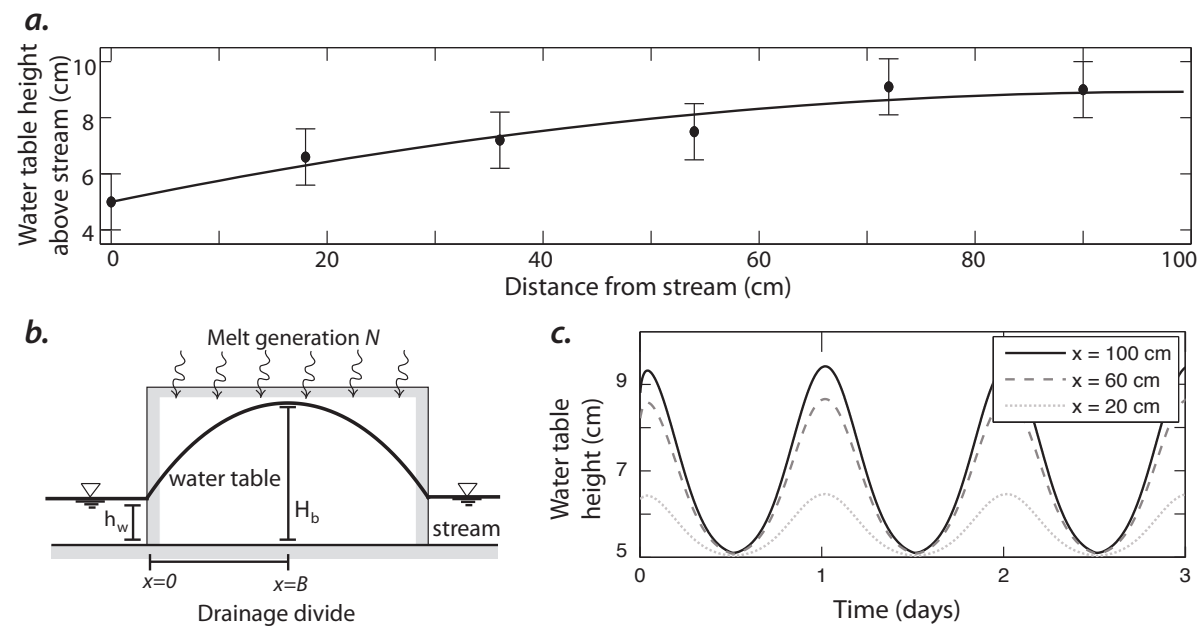

Fig. 4. (a) Water table height measurements as a function of distance away from a stream, with nonlinear fit of Eqs. (3) and (4), assuming $n_{0}=0.01 \mathrm{~m} \mathrm{~h}^{-1}$ and peak melting, $B=1 \mathrm{~m}, h_{w}=0.05 \mathrm{~m}, \phi=0.1$ and $k=1 \times 10^{-11} \mathrm{~m}^{2}$. Error bars are $1 \mathrm{~cm}$. (b) Sketch of the model problem and geometry, illustrating the Dupuit-Forchheimer ellipse. (c) Variation of water table height $h(x, t)$ from numerical solution to Eq. (3) parameters as in panel (a). Curves plot points along the profile as a function of time.

streams is consistent with a rather immature supraglacial channel network. Streams combine downstream, and all eventually empty into a shallow ice-marginal lake (Fig. 2a) or moulins near a medial moraine that bounds our site. Discharge thus increases with distance downstream except where water drains into moulins. Channel sinuosity is generally low, for example one channel surveyed in detail with GPS exhibits a sinuosity of 1.32 over a distance of $550 \mathrm{~m}$. However, small amplitude and regular meandering is common (Fig. 2d). We find that observed channel sinuosity follows the empirical scaling between the supraglacial channel width and meander wavelength observed worldwide (wavelength $=8.014 \pm 0.517 \times$ channel width over three orders of magnitude in channel width; Karlstrom et al., 2013).

\subsection{Permeability of near-surface ice, method 1}

To estimate near-surface permeability, we utilize two methods. The first method uses measurements of water table elevation in near-surface ice perpendicular to a stream high in the drainage basin to infer transport. Porous subsurface ice is a thin unconfined aquifer perched above a less permeable ice layer, in which meltwater flows down hydraulic gradients to streams. Because production of melt is strongly diurnal, the height of the aquifer varies in time and we use water table measurements along with a model of melt forcing to infer ice permeability.

After picking a drainage divide between two channels high in the drainage network that is roughly $1 \mathrm{~m}$ in length (total channel spacing of $2 \mathrm{~m}$ ), in a transect away from one stream we take multiple cores to expose the water table (Fig. 4a). In the hole left behind from each core, the position of the water table is recorded in terms of its depth below the glacial surface. Cores revealed dry, porous ice (grain size 1-2 cm) near to the surface and fully saturated ice near the bottom (below the water table). We observe a wetting front that extends $\sim 1-2 \mathrm{~cm}$ above the water table. The water table itself rises towards the glacier surface as a function of distance away from the stream, $5 \mathrm{~cm}$ over $1 \mathrm{~m}$ horizontally above the stream's base level (Fig. 4a).

Permeability may be estimated from these measurements by assuming spatially homogenous subsurface properties, then solving the equations for flow in a perched, unconfined aquifer in 1-D. Similar flows governed by similar equations also occur in soils and rocks (e.g., Manga, 1999). We can infer permeability by fitting observed water table elevation changes to a solution of the Boussinesq equation, obtained by combining Darcy's law for porous flow with continuity of water, forced by influx due to melting $N$ that is assumed constant over the domain $x$ but time variable:

$\frac{\partial h}{\partial t}=\kappa \frac{\partial^{2} h^{2}}{\partial x^{2}}+\frac{N(t)}{\phi}$,

where $\kappa=k g \rho / \mu \phi$ with $k$ the permeability, $\rho$ water density, $\mu$ water viscosity, $g$ gravity and $\phi$ the porosity.

For two streams at the same elevation separated by a divide of length $2 B$ (Fig. 4b), if $N$ is constant in time the exact solution to Eq. (1) for water table height $h$ is the DupuitForchheimer ellipse (Bear, 1972):

$h=\left[h_{w}^{2}+\frac{N(2 B-x) x}{\kappa}\right]^{1 / 2}$,

where $h_{w}$ is the (assumed equal) depth of the streams. The maximum elevation of the water table above the stream is $H_{b}=\sqrt{h_{w}^{2}+N B^{2} / \kappa}$. 
Ice screws inserted in the glacier surface provide estimates of melt rate during peak solar forcing of $\sim 1 \mathrm{~cm} \mathrm{~h}^{-1}$, a crude method that nonetheless results in melt rates roughly similar to concurrent ablation estimates derived from TSL migration at the Lemon Creek glacier on the western side of the Juneau Icefield of 0.03-0.04 $\mathrm{m} \mathrm{day}^{-1}$ (Mernild et al., 2013). We could use these as an estimate of $N$ in Eq. (2). However, such influx rates are comparable to spatial subsurface water table changes from the stream, implying that the water surface height should not be considered steady in time. Measured water table elevations are small compared to the available porous layer in the ice (estimated to be $0.25-0.5 \mathrm{~m}$ in thickness) so a linearized version of the Boussinesq equation is appropriate. This common approximation is valid when water table height changes are small compared to the mean water height $h_{0}$ (e.g., $h^{\prime} \ll h_{0}$ ):

$\frac{\partial h^{\prime}}{\partial t}=\kappa h_{0} \frac{\partial^{2} h^{\prime}}{\partial x^{2}}+\frac{N(t)}{\phi}$.

We take $N$ in the form

$$
N(t)=n_{0} e^{-(t-\operatorname{nint}(t))^{2} / \sigma^{2}},
$$

where $t$ is simulation time in days (measured in days here for $N(t)$ ), nint refers to "next integer" and $\sigma=6 \mathrm{~h}$, to model diurnal forcing with dominant $12 \mathrm{~h}$ melting period. We then solve this equation numerically with a Crank-Nicolson method, subject to boundary conditions that $h^{\prime}=h_{w}$, the stream depth at the channel outlet $x=0$ and that $\partial h^{\prime} / \partial x=0$ at $x=B$, taken to be $1 \mathrm{~m}$ from our measurements. $h_{w} \sim 5 \mathrm{~cm}$ in the channel nearest our measurements, and $h_{0}=0.25 \mathrm{~m}$. We estimate $n_{0} \sim 1 \mathrm{~cm} \mathrm{~h}^{-1}$ and porosity as $\phi \sim 10 \%$ similar to other firn studies (Fountain, 1989) although we consider these to be the most uncertain of parameter estimates (noting that melt rate $N$ likely varies more than porosity $\phi$ ). Other functional forms for melt rate Eq. (4) over a $12 \mathrm{~h}$ cycle (e.g., a sinusoid) do not affect the results.

We assume that all meltwater infiltrates into the perched aquifer, and thus neglect evaporation/sublimation. This can be justified by estimating the latent heat flux at our site, for which we use Eq. (5.28) of Cuffey and Paterson (2010). We have daily average relative humidity of $78 \%$, wind speed of $6.8 \mathrm{~m} \mathrm{~s}^{-1}$ and temperature $7.8^{\circ} \mathrm{C}$. These values give a latent heat flux of $-68 \mathrm{~W} \mathrm{~m}^{2}$, which corresponds to evaporation/sublimation rates of $\sim 0.001 \mathrm{~m} \mathrm{~h}^{-1}, \leq 1 \%$ of our inferred melting rate.

Numerical results (Fig. 4c) show that water surface height varies diurnally. Because our measurements were taken near peak melting (13:00 local time), we use the maximum calculated water table height and perform a Newton-Raphson iteration to find the permeability that minimizes the difference between modeled and measured water table in a least squares sense (solid line in Fig. 4a), assuming $h_{w}=0.05 \mathrm{~m}$, $B=1 \mathrm{~m}$, and $h_{0}=0.25 \mathrm{~m}$. For our measured $n_{0} \sim 1 \mathrm{~cm} \mathrm{~h}^{-1}$ on the Llewellyn Glacier we estimate $k \approx 1 \times 10^{-11} \mathrm{~m}^{2}$, with
$H_{b}-h_{0} \sim 5 \mathrm{~cm}$ the water table height above the stream, similar to estimates based on the static solution Eq. (2) with peak melting rate. In general there is a linear trade off between the ratio of melt rate to porosity $n_{0} / \phi$ and permeability for this model (illustrated with the exact solution, Eq. (2) in Fig. 7a).

\subsection{Permeability of near-surface ice, method 2}

Our second method for estimating permeability uses time series measurements of stream flow and water temperature, in a section of stream $\sim 100 \mathrm{~m}$ lower in the drainage basin than that surveyed for method 1 . If surface ice is at the melting point, solar radiation during daylight hours will induce melting. Once melting has occurred, additional solar radiation will heat water above the melting temperature. Thus we might expect diurnal variations of meltwater temperature for sufficient solar heating, lagged by the heating time for channels.

This heating time in general reflects a competition between thermal diffusion through water depth $D$, and advection of stream water down a channel reach (take scale length $L$ ) encapsulated by a Péclet number for the stream $P e=V D^{2} /\left(L \kappa_{d}\right)$, where $V$ is a scale velocity and $\kappa_{d}=$ $1.5 \times 10^{-7} \mathrm{~m}^{2} \mathrm{~s}^{-1}$ is the water thermal diffusivity. For small streams in the upper parts of the drainage basin, $D \sim 1 \mathrm{~cm}, V \sim 1-10 \mathrm{~mm} \mathrm{~s}^{-1}$ and $L \sim 1-5 \mathrm{~m} . P e=0.1-6 \leq$ $\mathcal{O}(1)$, demonstrating that water heating through diffusion over the stream depth likely dominates advection. The diffusion time for solar radiation is then $D^{2} / \kappa_{d} \sim 0.01^{2} / 1.5 \times$ $10^{-7} \sim 11 \mathrm{~min}$. This is much shorter than the period of diurnal heating, so some temperature variability is to be expected in supraglacial streams. Solar heating of meltwater will therefore be an indirect tracer of melting surrounding ice, which also closely tracks downward radiation (Marston, 1983). We expect that slower porous transport of freshly melted ice to streams will then cause a lag between increases in water temperature and stream discharge (e.g., McGrath et al., 2010; Munro, 2011) that may be used to infer permeability of the porous flow region.

DTS temperature measurements in the surveyed Llewellyn stream show differences in day-to-night water temperatures. Raw DTS traces (Fig. 5a) resolve lengths of cable running over ice and cable submerged in water, with marked temperature differences between the two that decrease during nighttime when solar radiation does not heat the cable exposed directly to air. Because discharge varies diurnally, the length of cable submerged in the small channel varies as a function of time, with a fraction of the cable exposed to the air at night when discharge is low. This exposed cable is clearly distinguished in the temperature signal (grey versus black curves at different times of day in Fig. 5a) and may be removed during post processing via thresholding. We therefore focus only on lengths of cable submerged in water, averaging over total submerged length to get a time series of average stream water temperature. A $24 \mathrm{~h}$ time series of DTS measurements during 

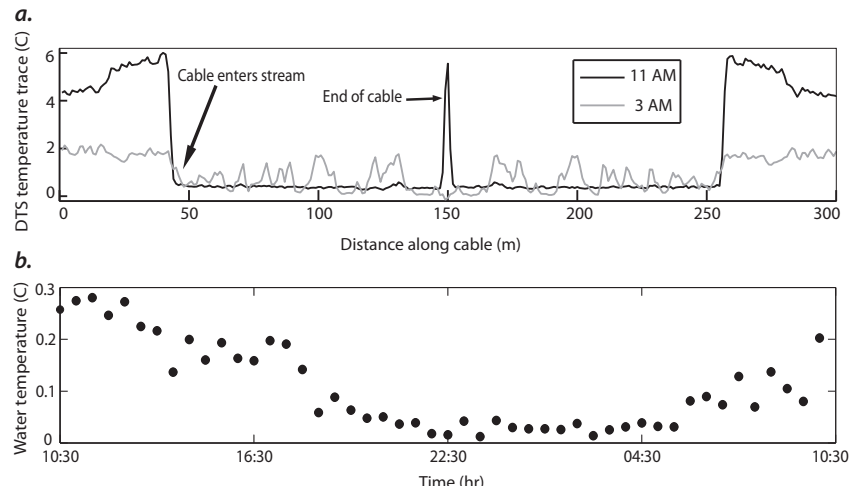

Fig. 5. (a) Unfiltered DTS temperature trace at 11:00 local time (black curve) and 03:00 local time (grey curve). The cable runs from the sensor to a water bath (not plotted), over glacier ice to the stream. The point of cable entry into the stream and end of cable (these are double-ended measurements, so trace is symmetric about midpoint) are labeled. (b) DTS time series over $24 \mathrm{~h}$ on a clear day, filtered spatially and averaged for water temperature. Each point is the $30 \mathrm{~min}$ average temperature along the submerged length of the cable.

a cloudless day on the surveyed stream (peak discharge of $0.013 \mathrm{~m}^{3} \mathrm{~s}^{-1}$ ) show a smoothly varying water temperature between $\sim 0$ and $0.3^{\circ} \mathrm{C}$ (Fig. 5 b), consistent with other measurements of supraglacial stream water temperature (Isenko et al., 2005).

While we do not measure discharge with the same time resolution as temperature, the length of cable submerged in the channel is a proxy for relative discharge because the instrumented reach has consistent (straight) geometry and the cable is well fixed in place with ice screws. We observe the expected lag between peak temperature and discharge (Fig. 6a). This lag as discussed above likely corresponds to the timescale of porous flow from the weathered ice aquifer into supraglacial channels, if we assume that peak water temperature corresponds to peak melting (and ice that is at the melting point). By fitting sinusoids with a $24 \mathrm{~h}$ period to these time series, we determine a best fit lag of $\tau=2.63 \mathrm{~h}$ between peak temperature and peak discharge, with some uncertainty in this estimate due to the $30 \mathrm{~min}$ signal integration performed for each DTS measurement. We can use the observed lag between peak discharge and water temperature (Fig. 6a) to infer a permeability from our solution to Eq. (3), which also exhibits a lag between forcing and discharge (proportional to $\partial h^{\prime} / \partial x$ at $x=0$, Fig. $6 \mathrm{~b}$ ).

Using model parameters as with method 1 , a value of $k \approx 0.5 \times 10^{-11} \mathrm{~m}^{2}$ produces the observed phase lag between melting and discharge at the stream. However because this channel is lower in the drainage basin than that for which we measure the water table, the distance between channels is larger (Fig. 3b), and therefore the recharge distance $B$ is likely larger when solving Eq. 3). Calculated lag times are insensitive to the magnitude of melt influx $n_{0}$ because a.
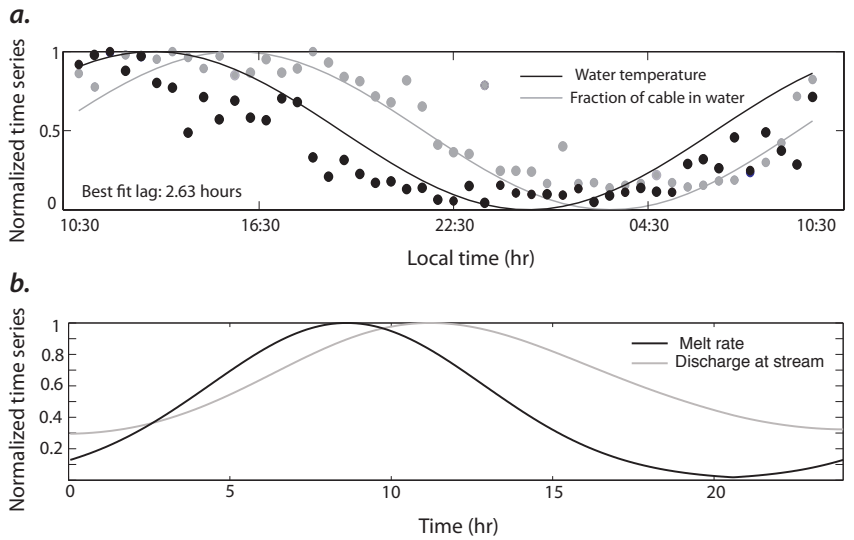

Fig. 6. (a) Lag between normalized time series of DTS temperature and fraction of cable in water (Fig. 5) with nonlinear fits of daily-periodic sinusoids. (b) Modeled time lag between discharge at channel outlet and melt input (assumed constant over the domain). Length of recharge is $B=10 \mathrm{~m}$, all other parameters as in Fig. 4 .

we are only concerned with the relative peak in discharge and $n_{0}$ is spatially homogeneous in our model. By fixing $n_{0}=1 \mathrm{~cm} \mathrm{~h}^{-1}$ but varying $B$, and setting all other parameters as in the previous calculation, we find a range of permeabilities as a function of $B$ that fits the observed time phase lag of $2.63 \mathrm{~h}$ (Fig. $7 \mathrm{~b}$ ). If we take $B=10 \mathrm{~m}$ as representative for the integrated upstream channels, we find $k=8 \times 10^{-11} \mathrm{~m}^{2}$.

\section{Discussion and conclusions}

We have estimated permeability of near-surface ice high in the ablation zone of the Llewellyn Glacier, using two independent methods that link observed drainage network properties to near-surface glacial hydrology. Permeability inferred by measuring water table elevation away from a stream (method 1) is consistent within an order of magnitude to permeability estimated from lag times between peak temperature and peak discharge (method 2, Fig. 7). The permeability inferred from method 2 is slightly larger, suggesting perhaps some scale dependence of permeability based on the larger length scales of the estimate $(\sim 10 \mathrm{~m}$ versus $\sim 1 \mathrm{~m}$ based on channel spacing differences within the drainage basin, Fig. 3). Scale dependence in near-surface permeability is common (e.g., Schulze-Makuch et al., 1999), although our current data do not allow for further investigation of this matter. Larger permeability on a $10 \mathrm{~m}$ scale than a $1 \mathrm{~m}$ scale would occur if, for example, fractures began to exert an influence on infiltration at the larger scale.

The permeabilities inferred by our measurements are 12 orders of magnitude smaller than permeabilities of nearsurface snow and firn (e.g., Sommerfeld and Rocchio, 1993; Campbell et al., 2006; Courville et al., 2010), values often employed for Darcy flow at the base of a snowpack or firn layer in the upper ablation zone (Arnold et al., 1998). Our 

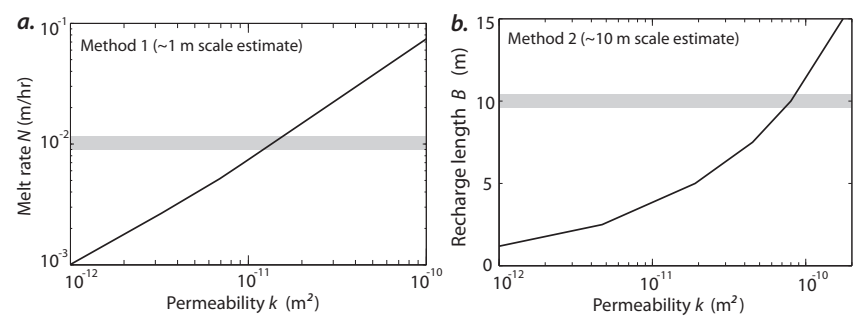

Fig. 7. Summary of permeability estimates from the two methods presented in the text. (a) Predicted permeability as a function of melt influx rate $N^{*}$ from Eq. (2) and Llewellyn Glacier water table measurements. We assume porosity of $\phi=0.1$ here. (b) Permeability estimated from matching the phase lag between discharge at stream and melt input (Fig. 6a) as a function of recharge length scale $B$. Estimates for melt rate (a) and recharge length (b) are shown with grey bars.

measurements are, however, similar to the $\sim 0.1-0.3 \mathrm{~m}$ scale of near-surface permeability measurements of sea ice at temperate latitudes (Kawamura et al., 2006) and, appropriately scaled, similar to hydraulic conductivities of firn reported by Schneider (1999).

The seasonal development of supraglacial stream networks reflects competition between surface melting, endogenic channelization instabilities and external control by underlying glacier structure. Supraglacial hydrology directly couples surface processes to solar forcing, so characterizing this system is important for understanding the response of glaciers and ice sheets to evolving surface energy balance. As the accumulation and retention of meltwater has considerable variability in large-scale systems such as the Greenland Ice Sheet (e.g., Braithwaite et al., 1994; Rennermalm et al., 2013), field-scale estimates of near-surface permeability may better inform models for surface runoff and energy balance (e.g., Bougamont and Bamber, 2005; Banwell et al., 2012a).

Many such models assume that friction-limited surface flow sets the transport rate of surface meltwater, for example into supraglacial lakes and moulins that then connect to the subglacial hydrological system. If flow is instead dominated by porous flow in weathered near-surface ice, these models will significantly underestimate the time scales of surface melt routing. Because the regime of supraglacial meltwater transport may vary spatially and in time, it may be important to model the development and seasonal evolution of channel networks and supraglacial drainage basins to predict the large-scale response of large ice masses to surface melting (Palmer et al., 2011).

As an illustration, we apply our methods to data from a study of western Greenland's supraglacial drainage in August 2009 made by McGrath et al. (2010). These authors provide a survey of channels comprising one drainage basin, and measure a phase lag between daily maximum melt production averaged over the basin and stream discharge measured at a moulin that drains the basin. Typical stream velocities are
$0.25-0.5 \mathrm{~m} \mathrm{~s}^{-1}, \sim 5$ orders of magnitude greater than likely Darcy velocities in the subsurface. Therefore, any phase lag between discharge and melting should be limited by transport of melt to streams. This will occur either through subsurface porous flow or via surface flow if the transport capacity of the subsurface is exceeded. We digitally measure via pixel counting the distance between 35 stream segments in Fig. 1 of McGrath et al. (2010), which yields a channel spacing of $18.0 \pm 6.7 \mathrm{~m}$ high in the drainage basin. Taking half this distance as the typical recharge length-scale $B$ in our model estimates (Fig. 4), we can use the measured phase lag of $2.8 \pm 4.2 \mathrm{~h}$ to estimate permeability of ice in this region as $k \approx 7 \times 10^{-11} \mathrm{~m}^{2}$. This is considerably smaller than permeabilities used in current models (Arnold et al., 1998). Although we advocate caution and site-specific calibration before directly applying our measurements on the Juneau Icefield to western Greenland, recent observations of an extensive firn aquifer in Greenland (Forster et al., 2013) suggest that the methods presented here may be useful for inferring near-surface permeability on a broader scale still.

Not all supraglacial environments exhibit a porous nearsurface region that accommodates significant subsurface porous flow, particularly if melt rates or external water input rates are high, or if local meteorological conditions promote ablation of the porous layer. A near-surface perched aquifer of meltwater is to be expected only where the creation of porosity/permeability (for example by differential absorption of solar radiation along grain boundaries, Müller and Keeler, 1969 ) is not outpaced by influx of meltwater from surroundings. Still, a layer of porous and/or fractured ice containing a subsurface water table is common (e.g., Fountain, 1989), and in these settings the water table height will depend on a balance between time varying porosity creation and porous flow.

If macroscale characteristics of supraglacial drainage such as channel spacing generally reflect transport efficacy, our study provides a basis for remotely estimating permeability with models calibrated by field data. It suggests dependencies on the characteristic length scales of channels to complement other remote sensing techniques (e.g., Brown et al., 2012). By establishing a connection between near-surface ice permeability and channel spacing, we can connect microscale hydraulic characteristics of ablation zone surface ice to macroscale features that are observable in satellite imagery (e.g., Yang and Smith, 2013).

If calibrated and tested by longer period field measurements, the models presented here could have application in the remote study of seasonal meltwater routing evolution on large scales that are otherwise inaccessible to direct observation. Generally, in western Greenland, supraglacial lake occurrence, longevity and size covary with melt intensity (Liang et al., 2012), and subsurface flow and storage may contribute significantly to Greenland's meltwater budget (Forster et al., 2013). Similarly, controls on supraglacial stream occurrence and spacing such as 
near-surface permeability likely vary seasonally and year to year. Because surface flow sets the timescale for supraglacial lake filling and subsequent draining (Hoffman et al., 2011; Banwell et al., 2012a, b), better constraints on field-scale, near-surface permeability should help to better link glacier melt with glacier and ice sheet motion in general.

Acknowledgements. We thank Eran Hood for logistical help and comments, NorthStar Trekking and the Juneau Icefield Research Program for logistical support, GSA and the UC Berkeley Behman fund for graduate student field work grants to L. Karlstrom, and the Ramsden fund for support to A. Zok. We thank Scott Tyler and CTEMPs for a student grant to use DTS equipment, and Ronnie Wentzel for gathering GPS data. We thank J. Walder, M. Pelto and an anonymous reviewer for constructive comments, and Johnny Sanders for glaciological field equipment.

Edited by: M. Sharp

\section{References}

Albert, M., Shultz, E., and FR Perron, J.: Snow and firn permeability at Siple Dome, Antarctica, Ann. Glaciol., 31, 353-356, 2000.

Arnold, N., Richards, K., Willis, I., and Sharp, M.: Initial results from a distributed, physically based model of glacier hydrology, Hydrol. Process., 12, 191-219, 1998.

Banwell, A., Arnold, N., Willis, I., Tedesco, M., and Alstrom, A.: Modeling supraglacial water routing and lake filling on the Greenland Ice Sheet, J. Geophys. Res., 117, F04012, doi:10.1029/2012JF002393, 2012a.

Banwell, A., Willis, I., Arnold, N., Messerli, A., Rye, C., and Ahlstrom, A.: Calibration and validation of a high resolution surface mass balance model for Paakitsoq, west Greenland, J. Glaciol., 58, 1047-1062, 2012b.

Bear, J.: Dynamics of Fluids in Porous Media, Dover Publications, New York, 1972.

Bougamont, M. and Bamber, J. L.: A surface mass balance model for the Greenland Ice Sheet, J. Geophys. Res., 110, F04018, doi:10.1029/2005JF000348, 2005.

Braithwaite, R. J., Laternser, M., and Pfeffer, W. T.: Variations of near-surface firn density in the lower accumulation area of the Greenland ice sheet, Pakitsoq, West Greenland, J. Glaciol., 40, 477-485, 1994.

Brown, J., Bradford, J., Harper, J., Pfeffer, W., Humphrey, N., and Mosley-Thompson, E.: Georadar-derived estimates of firn density in the percolation zone, western Greenland ice sheet, J. Geophys. Res., 117, F01011, doi:10.1029/2011JF002089, 2012.

Campbell, F., Nienow, P., and Purves, R.: Role of the supraglacial snowpack in mediating meltwater delivery to the glacier system as inferred from dye tracer experiments, Hydrol. Process., 20, 969-985, 2006.

Courville, Z., Horhold, M., Hopkins, M., and Albert, M.: LatticeBoltzmann modeling of the air permeability of polar firn, J. Geophys. Res., 115, F04032, doi:10.1029/2009JF001549, 2010.

Cuffey, K. M. and Paterson, W.: The Physics of Glaciers, Butterworth-Heinemann, 2010.

Das, S. B., Joughin, I., Behn, M. D., Howat, I. M., King, M. A., Lizarralde, D., and Bhatia, M. P.: Fracture Propoagation to the Base of the Greenland Ice Sheet During Supraglacial Lake Drainage, Science, 320, 778-781, doi:10.1126/science.1153360, 2008.

Forster, R., Box, J., van den Broeke, M., Miège, C., Burgess, E., van Angelen, J., Lenaerts, J., Koenig, L., Paden, J., Lewis, C., Gogineni, S., Leuschen, C., and McConnell, J.: Extensive liquid meltwater storage in firn within the Greenland ice sheet, Nat. Geosci., 7, 95-98, 2013.

Fountain, A. G.: The storage of water in, and hydraulic characteristics of, the firn of South Cascade Glacier, Washington State, USA, Ann. Glaciol., 13, 69-75, 1989.

Fountain, A. G. and Walder, J. S.: Water flow through temperature glaciers, Rev. Geophys., 36, 299-328, 1998.

Hoffman, M., Catania, G., Neumann, T., Andrews, L., and Rumrill, J.: Links between acceleration, melting, and supraglacial lake drainage of the western Greenland Ice Sheet, J. Geophys. Res., 116, F04035, doi:10.1029/2010JF001934, 2011.

Iken, A.: Measurements of water pressure in moulins as part of a movement study of the White Glacier, Axel Heiberg Island, Northwest Territories, Canada, J. Glaciol., 11, 53-58, 1972.

Iken, A. and Truffer, M.: The relationship between subglacial water pressure and velocity of Findelengletscher, Switzerland, during its advance and retreat, J. Glaciol., 43, 328-338, 1997.

Isenko, E., Narus, R., and Mavlyudov, B.: Water temperature in englacial and supraglacial channels: Change along the flow and contribution to ice melting on the channel wall, Cold Regions Sci. Technol., 42, 53-62, 2005.

Kamb, B., Engelhardt, H., Fahnestock, M., Humphrey, N., Meier, M., and Stone, D.: Mechanical and hydrologic basis for the rapid motion of a large tidewater glacier, J. Geophys. Res., 99, 1523115244, 1994.

Karlstrom, L., Gajjar, P., and Manga, M.: Meander formation in supraglacial streams, J. Geophys. Res., 118, 1897-1907, doi:10.1002/jgrf.20135, 2013.

Kawamura, T., Ishikawa, M., Takatsuka, T., Kojima, S., and Shirasawa, K.: Measurements of permeability of sea ice, Proceedings of the 18th IAHR International Symposium on Ice, 105112, 2006.

Knighton, A. D.: Channel Form and Flow Characteristics of Supraglacial Streams, Austre Okstindbreen, Norway, Arctic Alpine Res., 13, 295-306, 1981.

Liang, Y.-L., Colgan, W., Lv, Q., Steffen, K., Abdalati, W., Stroeve, J., Gallaher, D., and Bayou, N.: A decadel investigation of supraglacial lakes in West Greenland using a fully automatic detection and tracking algorithm, Remote Sens. Environ., 123, 127-138, 2012.

Manga, M.: On the timescales characterizing groundwater discharge at springs, J. Hydrol., 219, 56-69, 1999.

Marston, R. A.: Supraglacial Stream Dynamics on the Juneau Icefield, Annals of the Association of American Geographers, 73, 597-608, 1983.

McGrath, D., Colgan, W., Steffen, K., Lauffenburger, P., and Ba$\log$, J.: Assessing the summer water budget of a moulin basin in the Sermeq Avannarleq ablation region, Greenland ice sheet, J. Glaciol., 56, 954-964, 2010.

Mernild, S., Pelto, M., Malmros, J., Yde, J., Knudsen, N., and Hanna, E.: Indentification of snow ablation rate, ELA, AAR and net mass balance using transient snowline variations on two Arctic glaciers, J. Glaciol., 59, 649-659, 2013. 
Morris, E. and Wingham, D.: The effect of fluctuations in surface density, accumulation and compaction on elevation change rates along the EGIG line, central Greenland, J. Glaciol., 57, 416-430, 2011.

Müller, F. and Iken, A.: Velocity fluctuations and water regime of arctic valley glaciers, International Association of Scientific Hydrology, 95, 165-182, 1973.

Müller, F. and Keeler, C.: Errors in short-term ablation measurements on melting ice surfaces, J. Glaciol., 8, 91-105, 1969.

Munro, D.: Delays of supraglacial runoff from differently defined microbasin areas on the Peyto Glacier, Hydrol. Process., 25, 2983-2994, 2011.

Palmer, S., Shepherd, A., Nienow, P., and Joughin, I.: Seasonal speedup of the Greenland Ice Sheet linked to routing of surface water, Earth Planet. Sci. Lett., 302, 423-428, 2011.

Pelto, M.: Utility of late summer transient snowline migration rate on Taku Glacier, Alaska, The Cryosphere, 5, 1127-1133, doi:10.5194/tc-5-1127-2011, 2011.

Pelto, M., Kavanaugh, J., and McNeil, C.: Juneau Icefield Mass Balance Program 1946-2011, Earth Syst. Sci. Data, 5, 319-330, doi:10.5194/essd-5-319-2013, 2013.

Pfeffer, W., Meier, M., and Illanasekare, T.: Retention of Greenland runoff by refreezing: Implications for projected future sea level change, J. Geophys. Res., 96, 22117-22124, 1991.
Rennermalm, A., Moustafa, S., Mioduszewski, J., Chu, V., Forster, R., Hagedorn, B., Harper, J., Mote, T., Robinson, D., Shuman, C., Smith, L., and Tedesco, M.: Understanding Greenland ice sheet hydrology using an integrated multi-scale approach, Environ. Res. Lett., 8, 015017, doi:10.1088/1748-9326/8/1/015017, 2013.

Schneider, T.: Water movement in the firn of Storglaciären, Sweden, J. Glaciol., 45, 286-294, 1999.

Schulze-Makuch, S., Carlson, D., Cherkauer, D., and Malik, P.: Scale dependency of hydraulic conductivity in heterogeneous media, Ground Water, 37, 904-919, 1999.

Sommerfeld, R. and Rocchio, J.: Permeability measurements on new and equitemperature snow, Water Resour. Res., 29, 2485 2490, 1993.

Tyler, S. W., Selker, J. S., Hausner, M. B., Hatch, C. E., Torgersen, T., Thodal, C. E., and Schladow, S. G.: Environmental temperature sensing using Raman spectra DTS fibre-optic methods, Water Resour. Res., 45, W00D23, doi:10.1029/2008WR007052, 2009.

Yang, K. and Smith, L.: Supraglacial streams on the Greenland Ice Sheet delineated from combined spectral-shape information in high-resolution satellite imagery, IEEE Geosci. Remote Sens. Lett., 10, 801-805, doi:10.1109/LGRS.2012.2224316, 2013. 